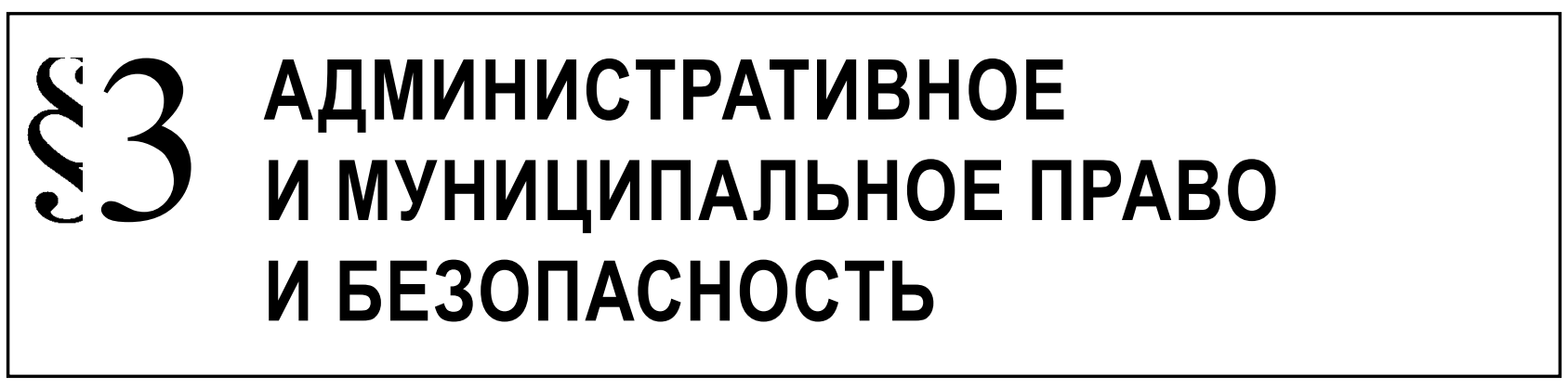

Миронов А.Н.

\title{
ПРАВОВЫЕ ОСНОВЫ ДЕЯТЕЛЬНОСТИ ОРГАНОВ МЕСТНОГО САМОУПРАВЛЕНИЯ ПО ОБЕСПЕЧЕНИЮ ОБЩЕСТВЕННОЙ БЕЗОПАСНОСТИ (НА ПРИМЕРЕ ВЛАДИМИРСКОЙ ОБЛАСТИ)
}

Аннотация: В качестве объекта исследования выступает деятельность органов государственной власти и органов местного самоуправления Владимирской области по созданию правовых условий обеспечения общественной безопасности на территории муниципальных образований. На основе анализа концепции общественной безопасности выделяются различные направления деятельности органов и должностных лиц местного самоуправления по обеспечению общественной безопасности, а также конкретные действия, осуществляемые в рамках различных направлений обеспечения общественной безопасности на территории муниципальных образований Владимирской области. Проведен анализ муниципально-правовых актов, регламентирующих деятельность различных видов муниципальных образований по обеспечению общественной безопасности Решение поставленных задач осуществлялось при помощи диалектического метода и основанных на нем современных общенаучных и частнонаучных средств и способов познания правового регулирования отношений по обеспечению общественной безопасности. Научная новизна состоит в комплексном анализе правовых основ организации и деятельности органов местного самоуправления по обеспечению общественно безопасности на территории Владимирской области, выделении направлений деятельности органов местного самоуправления. Автором отмечается отсутствие четко закрепленных полномочий органов местного самоуправления по обеспечению общественной безопасности, необходимых организационных и финансовых возможностей на местном уровне.

Ключевые слова: общественная безопасность, местное самоуправление, профилактика, коррупция, экстремизм, чрезвычайная ситуация, правонарушения, обеспечение, защита, общественный порядок.

Review: The object of the research is the activity of the state authorities and the local governments of Vladimir region in the creation of legal conditions of public security provision on the municipal territories. On the base of the analysis of the concept of public security the author outlines the various activities of the local bodies and officials in the sphere of public security, as well as the specific actions taken within the various spheres of public security on the municipal territories of Vladimir region. The author analyzes the municipal legal acts regulating the activities of various types of municipalities in the sphere of public safety provision. The solution is based on the dialectical method and the related scientific methods of cognition of legal regulation of relations in the sphere of public safety. The scientific novelty consists in a comprehensive analysis of the legal foundations of the organization and activities of local authorities in the sphere of public safety on the territory of Vladimir region, the revelation of the local governments' activites. The author notes the lack of clearly established responsibilities of the local governments in the sphere of public safety provisioin, the necessary organizational and financial capacities at the local level.

Keywords: provision, crimes, emergencies, extremism, corruption, prevention, local government, public safety, protection, public order.

0 беспечение общественной безопасности Российской Федерации является необходимым условием стабильного и поступательного развития общества и государства, создания достойных условий и качества жизни граждан, а также формирования благоприятных внутренних и внешних условий для достижения приоритетов в области социально-экономического развития государства. 
В системе основных общегосударственных мер по защите жизни и здоровья, прав и свобод граждан, законных интересов предприятий, учреждений, организаций и общественных объединений особое место отводится общественной безопасности, так как она является одной из важнейших составляющих всей системы безопасности государства. Обеспечение общественной безопасности, в том числе защита жизни и здоровья, прав и свобод граждан, законных интересов предприятий, учреждений, организаций и общественных объединений невозможно без установления ограничений закрепленных в основном законе нашего государства, прав и свобод как физически, так и юридических лиц.

Правовую основу обеспечения общественной безопасности составляют Конституция Российской Федерации, общепризнанные принципы и нормы международного права, международные договоры Российской Федерации, федеральные конституционные законы, Федеральный закон от 7 февраля 2011 г. № 3-Ф3 «0 безопасности» [1], иные федеральные законы, нормативные правовые акты Президента Российской Федерации и Правительства Российской Федерации, Стратегия национальной безопасности Российской Федерации до 2020 года, Концепция общественной безопасности в Российской Федерации [2], а также нормативные правовые акты федеральных органов исполнительной власти, конституции (уставы), законы и иные нормативные правовые акты субъектов Российской Федерации, уставы муниципальных образований и иные муниципальные правовые акты.

Обеспечение общественной безопасности осуществляется всей системой действующих на территории Российской Федерации органов и учреждений. Не составляют исключения и органы местного самоуправления.

Содержание деятельности по обеспечению безопасности во многом определяется пониманием общественной безопасности. К сожалению, отсутствие законодательного закрепление понятия общественной безопасности создает возможности для многозначительного её понимания различными авторами.

А.И. Сапожников определяет общественную безопасность как социально-правовое явление, под которым понимается совокупность общественных отношений, регулируемых системой юридических норм в целях предотвращения, локализации и ликвидации условий и факторов, создающих потенциальную или реальную опасность жизненно важным интересам граждан и обществу в целом [3].
Интересна точка зрения В.Н. Васина, он определяет «общественную безопасность» следующим образом: это «состояние обеспеченности общества мерами охраны и механизмом их реализации от преступных посягательств, антропогенных воздействий природной среды, аварий и катастроф» [4].

Наиболее полно определяет общественную безопасность Б.П. Кондрашов. Под общественной безопасностью он понимает «систему общественных отношений, урегулированных правовыми нормами в целях обеспечения безопасности личности, общественного спокойствия, благоприятных условий для труда и отдыха граждан, нормальной деятельности государственных органов, общественных объединений, предприятий, учреждений и организаций от угрозы, исходящей от преступных и иных противоправных деяний, нарушения порядка пользования источниками повышенной опасности, предметами и веществами, изъятыми из гражданского оборота, явлений негативного техногенного и природного характера, а также других особых обстоятельств» [5].

И.А. Макарычев определяет понятие «общественная безопасность» как «состояние защищенности нормами права определенной совокупности общественных отношений, складывающихся в области жизнедеятельности личности, общества и государства, безопасного функционирования органов государственной и муниципальной власти, общественных организаций (объединений) и граждан, а также гарантированной государством реализации их прав, свобод и законных интересов» [6].

Это далеко не полный перечень предлагаемых подходов к пониманию общественной безопасности, который всё же позволяет говорить о том, что содержание общественной безопасность может быть представлено очень широко.

Учитывая положения концепции общественной безопасности в Российской Федерации, обеспечение общественной безопасности предполагает использование различных мер:

а) по предупреждению, выявлению и пресечению террористической и экстремистской деятельности, преступлений, связанных с коррупцией, незаконным оборотом наркотических средств и психотропных веществ, оружия, боеприпасов, взрывчатых веществ, организацией незаконной миграции, торговлей людьми, а также других преступных посягательств на права и свободы человека и гражданина, материальные и духовные ценности общества, критически важные и (или) потенциально 
опасные объекты инфраструктуры Российской Федерации;

б) по профилактике социальных и межнациональных конфликтов;

в) по предупреждению, ликвидации и (или) минимизации последствий чрезвычайных ситуаций природного и техногенного характера, включая оказание первой помощи лицам, находящимся в беспомощном состоянии либо в состоянии, опасном для их жизни и здоровья;

г) по совершенствованию государственного управления в области пожарной, химической, биологической, ядерной, радиационной, гидрометеорологической, промышленной и транспортной безопасности;

д) по развитию международного сотрудничества в правоохранительной сфере, а также в области предупреждения чрезвычайных ситуаций природного и техногенного характера и ликвидации их последствий.

Интерес вызывают возможности в соответствии с действующей системой российского законодательства участвовать в обеспечении общественной безопасности органов и должностных лиц местного самоуправления, ведь они представляют собой низовое из звеньев в организации власти в государстве и во многом от их деятельности зависит реальность предоставляемых прав и свобод физическим и юридическим лицам и их обеспечение.

Основным законодательным актом, закрепляющим принципы организации местного самоуправления является Федеральный закон от 6 октября 2003 года №131-Ф3 «Об общих принципах организации местного самоуправления в Российской Федерации» [7] (далее - Ф3 №131), который определяет вопросы местного значения различных видов муниципальных образований в рамках обеспечения общественной безопасности. В зависимости от вида муниципального образования меняется и круг вопросов местного значения, касающийся обеспечения общественной безопасности.

Так, в соответствии с частью 1 статьи 14 Ф3 №131 к предметам городского и сельского поселения в рамках которых могут применяться меры по обеспечению общественной безопасности относятся:

- участие в профилактике терроризма и экстремизма, а также в минимизации и (или) ликвидации последствий проявлений терроризма и экстремизма в границах поселения;

- создание условий для реализации мер, направленных на укрепление межнационального и межконфессионального согласия, сохранение и развитие языков и культуры народов Российской Федерации, проживающих на территории поселения, социальную и культурную адаптацию мигрантов, профилактику межнациональных (межэтнических) конфликтов;

- участие в предупреждении и ликвидации последствий чрезвычайных ситуаций в границах поселения;

- $\quad$ обеспечение первичных мер пожарной безопасности в границах населенных пунктов поселения;

- создание условий для массового отдыха жителей поселения и организация обустройства мест массового отдыха населения, включая обеспечение свободного доступа граждан к водным объектам общего пользования и их береговым полосам;

- организация и осуществление мероприятий по территориальной обороне и гражданской обороне, защите населения и территории поселения от чрезвычайных ситуаций природного и техногенного характера;

- создание, содержание и организация деятельности аварийно-спасательных служб и (или) аварийно-спасательных формирований на территории поселения;

- осуществление мероприятий по обеспечению безопасности людей на водных объектах, охране их жизни и здоровья;

- оказание поддержки гражданам и их объединениям, участвующим в охране общественного порядка, создание условий для деятельности народных дружин;

- осуществление мер по противодействию коррупции в границах поселения.

На более крупные муниципальные образования дополнительно возлагаются полномочия по организации охраны общественного порядка муниципальной милицией, в частности на территории муниципального района или городского округа, которые до настоящего времени не могут быть реализованы в связи с отсутствием федерального законодательства о муниципальной милиции.

Ф3 № 131 в части 1.2 статьи 17 устанавливает одно из важных положений о том, что не допускается отнесение к полномочиям органов государственной власти субъекта Российской Федерации полномочий органов местного самоуправления по охране общественного порядка, что предполагает самостоятельность в его осуществлении именно органами местного самоуправления.

Закрепление на федеральном уровне общих принципов организации местного самоуправле- 
ния, в том числе и по обеспечению общественной безопасности, предполагает их дальнейшее развитие в законодательстве субъектов Российской Федерации и муниципальных образований.

Рассмотрим что сделано по данному вопросу во Владимирской области.

Первое из направлений - участие в профилактике терроризма и экстремизма, реализуется посредством установления мер, реализуемых на территории области как органами государственной власти, так органами местного самоуправления. Так, Постановлением Губернатора Владимирской обл. от 25 сентября 2013 г. № 1075 была утверждена государственная программа «Обеспечение общественного порядка и профилактики правонарушений во Владимирской области на 2013 - 2015 годы» [8].

Развитие положения программы получили и в муниципально-правовых актах, которыми были утверждены как отдельные программы $[9,10,11]$, предусматривающие профилактику правонарушений в целом, так и непосредственно направленные на профилактику терроризма и экстремизма $[12,13,14]$. В целом деятельность органов и должностных лиц местного самоуправления в данном направлении состоит в проведении профилактических, воспитательных и пропагандистских мер, направленных на предупреждение террористической экстремистской деятельности, а именно:

- участие в обеспечении населения наглядной агитационной информацией (включая средства массовой информации) предупредительного характера об угрозах террористической и экстремистской направленности;

- принятие правовых актов, касающихся организации, совершенствования и оценки эффективности деятельности организаций, предприятий и учреждений муниципального образования по профилактике терроризма и экстремизма;

- запрос и получение в установленном порядке необходимых материалов и информации от территориальных органов федеральных органов исполнительной власти, органов исполнительной власти Владимирской области, общественных объединений, организаций (независимо от форм собственности) и должностных лиц;

- привлечение для консультационной работы должностных лиц и специалистов;

- проведение совещаний, круглых столов, мероприятий, целевых акций, направленных на формирование толерантности и межэтниче- ской культуры в молодежной среде, на недопустимость агрессивного поведения и других.

Второе направление - участие в предупреждении и ликвидации последствий чрезвычайных ситуаций реализуется муниципальными образованиями путем, как правило, создания специальных органов $[15,16]$, на которые возлагается выполнение мероприятий в рамках рассматриваемого направления. Вместе с тем, судя по принятым муниципально-правовым актам это было сделано не во всех муниципальных образованиях, в связи с чем возможно говорить об отсутствии необходимых структур в муниципальных образованиях для выполнения мероприятий по предупреждению и ликвидации последствий возможных чрезвычайных ситуаций. Примерами выполняемых мероприятий в рамках данного направления могут быть:

- осуществление подготовки и содержания в готовности необходимых сил и средств для защиты населения и территорий от чрезвычайных ситуаций, обучение населения способам защиты и действиям в этих ситуациях;

- принятие решений о проведении эвакуационных мероприятий в чрезвычайных ситуациях и организация их проведения;

- осуществление информирования населения о чрезвычайных ситуациях;

- организация и проведение аварийно-спасательных и других неотложных работ, а также поддержание общественного порядка при их проведении, при недостаточности собственных сил и средств обращение за помощью к органам исполнительной власти субъектов Российской Федерации и др.

Следующее из направлений по обеспечению общественной безопасности - обеспечение общественного порядка на территории муниципального образования.

В настоящее время органы местного самоуправления выполняют следующие функции, имеющие отношение к охране общественного порядка:

- накладывают в пределах своей компетенции административные наказания на граждан и должностных лиц за совершенные ими административные правонарушения;

- принимают предусмотренные законодательством меры, связанные с проведением собраний, митингов, уличных шествий и демонстраций, организацией спортивных, зрелищных и других массовых мероприятий;

- у участвуют в пределах своей компетенции в обеспечении безопасности дорожного движения; 
- $\quad$ содействуют органам суда, прокуратуры и юстиции в их работе по обеспечению законности на территории муниципального образования;

- привлекают граждан, общественные организации, предприятия и учреждения к решению вопросов охраны общественного порядка;

- принимают в пределах своей компетенции решения в сфере охраны общественного порядка и профилактики правонарушений на территории соответствующего муниципального образования, не противоречащие действующему законодательству;

- совместно с горрайорганами внутренних дел определяют задачи по охране общественного порядка и профилактике правонарушений с учетом особенностей и обстановки на территории соответствующего муниципального образования [17].

Реализация функций в сфере общественного порядка на территории муниципального образования в настоящее время может осуществляться создаваемыми специально для этих целей муниципальными органами $[18,19,20,21,22]$, общественными формированиями и в перспективе муниципальной милицией [23]. Создание муниципальной милиции, по мнению авторов законопроекта, приблизит правоохранительную деятельность к потребностям граждан и конкретных поселенческих обществ, повысит подотчетность органов охраны правопорядка гражданам, а также уровень доверия к ним со стороны населения и в целом положительно скажется на состоянии безопасности граждан и общественного порядка в стране. Через муниципальную милицию могут быть открыты новые каналы связи общества и правоохранительных органов. Появится возможность создания условий для реализации стратегии социального партнерства, предполагающих обстановку взаимопонимания, доверия, взаимной поддержки и сотрудничества. Все это будет способствовать росту правовой активности людей, а в конечном итоге - повышению эффективности функционирования всей правоохранительной системы общества.

К сожалению, говорить об обеспечении общественного порядка муниципальной милицией пока не приходится в связи отсутствием правового регулирования на федеральном уровне. Деятельность же общественных объединений правоохранительной направленности регламентируется как на федеральном [24], региональном [25], так и местном уровне $[26,27]$. Вместе с тем деятельность указанных общественных формирований не обеспечена соответствующими правами и обязанностями, что не позволяет в должной мере участвовать в охране общественного порядка не опасаясь за свою жизнь и здоровье. Также отсутствуют какие либо гарантии в отношении граждан, участвующих в охране общественного порядка.

Кроме того по данному направлению деятельности является отсутствие как на федеральном уровне, так и на уровне Владимирской области законодательных актов, определяющих меры по профилактике правонарушений, что в ряде субъектов Российской Федерации было осуществлено.

И последнее направление, которое охватывается понятием общественная безопасность и реализуемое на местном уровне является осуществление мер по противодействию коррупции.

Положения статьи 2 Федерального закона от 25 декабря 2008 г. № 273-Ф3 «0 противодействии коррупции» [28] включили в правовую основу противодействия коррупции, помимо прочего, муниципальные правовые акты, что означает необходимость регулирования отдельных аспектов антикоррупционной политики органами местного самоуправления. Другие положения Федерального закона от 25 декабря 2008 г. № 273-ФЗ «0 противодействии коррупции» дают представление о вопросах, которые должны предусматриваться в соответствующих муниципальных правовых актах. Вместе с тем законодатель не счел необходимым применительно к органам местного самоуправления закрепить направления деятельности по противодействию коррупции, как это было сделано применительно к органам государственной власти.

И всё же деятельность органов местного самоуправления в этом направлении ведется исходя из принятых в данном направлении муниципальноправовых актов на территории Владимирской области [29, 30, 31, 32].

В заключении хотелось бы отметить следующее:

Во-первых, необходимо выработать четкое понимание общественной безопасности и её содержания;

Во-вторых, при принятии федерального законодательства обязательным представляется закрепление конкретных полномочий органов местного самоуправления по направлениям обеспечения безопасности, что, к сожалению, не всегда присутствует и создает сложности в их вычленении исходя из замысла законодателя;

В-третьих, обеспечение безопасности всегда связано с серьезными финансовыми затратами со стороны органов и должностных лиц местного самоуправления, а местные бюджеты не могут «по- 
тянуть» данные расходы самостоятельно, в связи с чем считаем выделение дополнительных финансовых средств местным бюджетам для реализации рассматриваемого направления деятельности.

В-четвертых, органы местного самоуправления выступают низовым звеном организации власти в государстве, в связи, с чем субъектам Рос- сийской Федерации необходимо не только координировать работу органов местного самоуправления в данном направлении, но и своевременно осуществлять правовое регулирование в сфере обеспечения общественной безопасности и оказывать методическую помощь органам и должностным лицам местного самоуправления.

\section{Библиография:}

1. Федеральный закон от 7 февраля 2011 г. № 3-ФЗ «О безопасности» // СЗ РФ. - 2011. - № 1. - Ст. 2.

2. Концепция общественной безопасности, утверждена Президентом РФ 14.11.2013 № Пр-2685 // Доступ из справ.правовой системы «КонсультантПлюс».

3. Сапожников А.И. Административно-правовой режим общественной безопасности: дис. канд. юрид. наук. - М., 2006.

4. Васин В.Н. Право на общественную безопасность: монография. - М.: ЮИ МВД России, 1999. С. 84.

5. Кондрашов Б.П. Общественная безопасность и административно-правовые средства ее обеспечения. - М.: Юрист, 1998. - С. 8.

6. Макарычев И. А. Административно-правовое обеспечение общественной безопасности органами муниципальной власти: дис. ... канд. юрид. наук. - Люберцы, 2010. 220с.

7. Федеральный закон от 6 октября 2003 года №131-Ф3 «Об общих принципах организации местного самоуправления в Российской Федерации» // СЗ РФ. - 2003. - № 40. - Ст.3822; - 2015. - № 1 (часть I). - Ст. 9.

8. Постановление Губернатора Владимирской области от 25.09 .2013 № 1075 «Об утверждении государственной программы «Обеспечение общественного порядка и профилактики правонарушений во Владимирской области на 2013-2015 годы» // Владимирские ведомости. - № 187. - 05.10.2013.

9. Постановление администрации Юрьев-Польского района от 28.10.2013 № 1437 «Об утверждении муниципальной программы «Обеспечение общественного порядка и профилактики правонарушений на территории муниципального образования Юрьев-Польский район на 2014-2016 годы» // Вестник Ополья. - № 112. - 26.12.2013.

10. Постановление главы Селивановского района от 08.11.2013 № 1099 «Об утверждении муниципальной программы «Обеспечение общественного правопорядка и профилактики правонарушений в Селивановском районе на 2013-2015 годы» // Доступ из справ.-правовой системы «КонсультантПлюс».

11. Постановление главы Гусь-Хрустального района от 12.11 .2013 № 1830 «Об утверждении муниципальной программы «Обеспечение общественного порядка и профилактики правонарушений в Гусь-Хрустальном районе на 2013-2015 годы» // Доступ из справ.-правовой системы «КонсультантПлюс».

12. Решение Совета народных депутатов Петушинского района от 20.03.2014 № 15/3 «Об утверждении Положения «Об участии в профилактике терроризма и экстремизма, а также минимизации и (или) ликвидации их последствий на территории муниципального образования «Петушинский район» // Доступ из справ.-правовой системы «КонсультантПлюс».

13. Постановление главы Судогодского района от 17.02.2011 № 231 «0 мерах по профилактике экстремизма на территории МО «Судогодский район» (вместе с «Положением об участии в профилактике экстремизма, а также минимизации и (или) ликвидации последствий проявлений экстремизма на территории Судогодского района») // Доступ из справ.-правовой системы «КонсультантПлюс».

14. Решение Совета народных депутатов Ковровского района от 30.10 .2008 № 53 «Об утверждении Положения «Об участии в профилактике терроризма и экстремизма, а также минимизации и (или) ликвидации их последствий на территории Ковровского района» // Знамя труда (спецвыпуск). - № 42. - 07.11.2008.

15. Постановление главы Петушинского района от 21.08.2006 № 1423 «Об участии в предупреждении и ликвидации последствий чрезвычайных ситуаций в Петушинском районе» (вместе с «Положением об участии в предупреждении и ликвидации последствий чрезвычайных ситуаций в Петушинском районе») // Вперед (Вестник органов местного самоуправления Петушинского района). - № 32. - 13.09.2006.

16. Постановление администрации г. Владимира от 29.09.2011 № 2554 «Об утверждении устава муниципального казенного учреждения «Управление гражданской защиты города Владимира» и о признании утратившим силу пункта 3 постановления главы города Владимира от 15.07.2005 № 252» // http://www.vladimir-city.ru/municipal/ documents/official/802451/

17. Алешкова Н.П. Проблемы реализации конституционной нормы о самостоятельности осуществления охраны общественного порядка органами местного самоуправления // Муниципальная служба: правовые вопросы. 2014. - № 1. - С. 6-9.

18. Закон Владимирской области от 30.12.2002 № 141-03 «Об административных комиссиях» // Владимирские ведомости. - № 5. - 10.01.2003.

19. Закон Владимирской области от 11.07.2014 № 79-03 «О комиссиях по делам несовершеннолетних и защите их прав во Владимирской области» // Владимирские ведомости. - № 136. - 19.07.2014.

20. Постановление главы округа Муром от 07.12.2011 № 3492 «0 создании административных комиссий № 1 и № 2 муниципального образования округ Муром» // Доступ из справ.-правовой системы «КонсультантПлюс». 
21. Постановление администрации города Владимира от 19.12 .2011 № 4059 «Об утверждении персонального состава административной комиссии муниципального образования город Владимир (городской)» // Перископ. № 204. - 24.12.2011.

22. Постановление главы Александровского района от 24.01.2011 № 272 «Об утверждении административных регламентов по исполнению муниципальных функций комиссией по делам несовершеннолетних и защите их администрации Александровского района» // Александровский голос труда. - № 15. - 13.04.2011.

23. Проект Федерального закона № 621910-6 «0 муниципальной милиции в Российской Федерации» находится на рассмотрении Государственной Думы ФС РФ.

24. Федеральный закон от 02.04.2014 № 44-Ф3 «Об участии граждан в охране общественного порядка» // СЗ РФ. 2014. - № 14. - Ст.1536.

25. Закон Владимирской области от 10.06.2013 № 60-03 «Об участии граждан в охране общественного порядка на территории Владимирской области» // Владимирские ведомости. - № 107. - 15.06.2013.

26. Решение Совета народных депутатов Селивановского района от 28.08.2013 № 75 «Об утверждении Положения об участии граждан в охране общественного порядка на территории Селивановского района» // Селивановский вестник. - № 54. - 30.08.2013.

27. Решение Совета народных депутатов ЗАТО г. Радужный от 16.09.2013 № 15/79 «Об утверждении Положения о создании условий для деятельности добровольных формирований населения по охране общественного порядка на территории ЗАТО г. Радужный Владимирской области» // Радуга-информ. - № 65. - 20.09.2013.

28. Федеральный закон от 25 декабря 2008 г. № 273-ФЗ «О противодействии коррупции» // СЗ РФ. - 2008. - № 52 (ч. 1). - Ст. 6228; - 2014. - № 52 (часть I). - Ст. 7542.

29. Постановление главы Селивановского района от 25.05.2012 № 485 «Об утверждении плана «Противодействие коррупции в муниципальном образовании Селивановский район на 2012-2014 годы» // Доступ из справ.правовой системы «КонсультантПлюс».

30. Постановление администрации муниципального образования город Камешково Камешковского района Владимирской области от 16.07.2014 № 106 «Об утверждении положения о порядке и сроках применения взысканий к муниципальным служащим администрации муниципального образования город Камешково Камешковского района за несоблюдение ограничений и запретов, требований о предотвращении или об урегулировании конфликта интересов и неисполнение обязанностей, установленных в целях противодействия коррупции» // Доступ из справ.-правовой системы «КонсультантПлюс».

31. Постановление администрации Петушинского района от 28.02 .2014 № 396 «Об утверждении муниципальной программы «Противодействие коррупции в муниципальном образовании «Петушинский район» на 2014-2016 годы» // Вперед. - № 31. - 4-10 июля. - 2014.

32. Решение Совета народных депутатов округа Муром от 22.02 .2011 № 1220 «Об утверждении перечня должностей муниципальной службы, предусмотренного статьей 12 Федерального закона от 25.12.2008 № 273-Ф3 «О противодействии коррупции» // Муромский край (документы, выпуск № 15). - № 32. - 01.03.2011.

33. Камилов М.А. Определение общественной безопасности в соответствии с новой Концепцией общественной безопасности в Российской Федерации. // Административное и муниципальное право. - 2014. - 8. - С. 775 - 778. DOI: $10.7256 / 1999-2807.2014 .8 .12403$.

\section{References (transliterated):}

1. Federal'nyi zakon ot 7 fevralya 2011 g. № 3-FZ «O bezopasnosti» // SZ RF. - 2011. - № 1. - St. 2.

2. Kontseptsiya obshchestvennoi bezopasnosti, utverzhdena Prezidentom RF 14.11.2013 № Pr-2685 // Dostup iz sprav.pravovoi sistemy «Konsul'tantPlyus».

3. Sapozhnikov A.I. Administrativno-pravovoi rezhim obshchestvennoi bezopasnosti: dis. kand. yurid. nauk. - M., 2006.

4. Vasin V.N. Pravo na obshchestvennuyu bezopasnost': monografiya. - M.: YuI MVD Rossii, 1999. S. 84.

5. Kondrashov B.P. Obshchestvennaya bezopasnost' i administrativno-pravovye sredstva ee obespecheniya. - M.: Yurist, 1998. - S. 8.

6. Makarychev I. A. Administrativno-pravovoe obespechenie obshchestvennoi bezopasnosti organami munitsipal'noi vlasti: dis. ... kand. yurid. nauk. - Lyubertsy, 2010. 220s.

7. Federal'nyi zakon ot 6 oktyabrya 2003 goda №131-FZ «Ob obshchikh printsipakh organizatsii mestnogo samoupravleniya v Rossiiskoi Federatsii» // SZ RF. - 2003. - № 40. - St.3822; - 2015. - № 1 (chast' I). - St. 9.

8. Postanovlenie Gubernatora Vladimirskoi oblasti ot 25.09.2013 № 1075 «Ob utverzhdenii gosudarstvennoi programmy «Obespechenie obshchestvennogo poryadka i profilaktiki pravonarushenii vo Vladimirskoi oblasti na 2013-2015 gody» // Vladimirskie vedomosti. - № 187. - 05.10.2013.

9. Postanovlenie administratsii Yur'ev-Pol'skogo raiona ot 28.10.2013 № 1437 «Ob utverzhdenii munitsipal'noi programmy «Obespechenie obshchestvennogo poryadka i profilaktiki pravonarushenii na territorii munitsipal'nogo obrazovaniya Yur'ev-Pol'skii raion na 2014-2016 gody» // Vestnik Opol'ya. - № 112. - 26.12.2013.

10. Postanovlenie glavy Selivanovskogo raiona ot 08.11 .2013 № 1099 «Ob utverzhdenii munitsipal'noi programmy «Obespechenie obshchestvennogo pravoporyadka i profilaktiki pravonarushenii v Selivanovskom raione na 20132015 gody» // Dostup iz sprav.-pravovoi sistemy «Konsul'tantPlyus».

11. Postanovlenie glavy Gus'-Khrustal'nogo raiona ot 12.11 .2013 № 1830 «Ob utverzhdenii munitsipal'noi programmy «Obespechenie obshchestvennogo poryadka i profilaktiki pravonarushenii v Gus'-Khrustal'nom raione na 20132015 gody» // Dostup iz sprav.-pravovoi sistemy «Konsul'tantPlyus». 
12. Reshenie Soveta narodnykh deputatov Petushinskogo raiona ot 20.03.2014 № 15/3 «Ob utverzhdenii Polozheniya «Ob uchastii v profilaktike terrorizma i ekstremizma, a takzhe minimizatsii i (ili) likvidatsii ikh posledstvii na territorii munitsipal'nogo obrazovaniya «Petushinskii raion» // Dostup iz sprav.-pravovoi sistemy «Konsul'tantPlyus».

13. Postanovlenie glavy Sudogodskogo raiona ot 17.02 .2011 № 231 «0 merakh po profilaktike ekstremizma na territorii MO «Sudogodskii raion» (vmeste s «Polozheniem ob uchastii v profilaktike ekstremizma, a takzhe minimizatsii i (ili) likvidatsii posledstvii proyavlenii ekstremizma na territorii Sudogodskogo raiona») // Dostup iz sprav.-pravovoi sistemy «Konsul'tantPlyus».

14. Reshenie Soveta narodnykh deputatov Kovrovskogo raiona ot 30.10 .2008 № 53 «Ob utverzhdenii Polozheniya «Ob uchastii v profilaktike terrorizma i ekstremizma, a takzhe minimizatsii i (ili) likvidatsii ikh posledstvii na territorii Kovrovskogo raiona» // Znamya truda (spetsvypusk). - № 42. - 07.11.2008.

15. Postanovlenie glavy Petushinskogo raiona ot 21.08.2006 № 1423 «Ob uchastii v preduprezhdenii i likvidatsii posledstvii chrezvychainykh situatsii v Petushinskom raione» (vmeste $s$ «Polozheniem ob uchastii v preduprezhdenii i likvidatsii posledstvii chrezvychainykh situatsii v Petushinskom raione») // Vpered (Vestnik organov mestnogo samoupravleniya Petushinskogo raiona). - № 32. - 13.09.2006.

16. Postanovlenie administratsii g. Vladimira ot 29.09 .2011 № 2554 «Ob utverzhdenii ustava munitsipal'nogo kazennogo uchrezhdeniya «Upravlenie grazhdanskoi zashchity goroda Vladimira» i o priznanii utrativshim silu punkta 3 postanovleniya glavy goroda Vladimira ot 15.07.2005 № 252» // http://www.vladimir-city.ru/municipal/documents/ official/802451/

17. Aleshkova N.P. Problemy realizatsii konstitutsionnoi normy o samostoyatel'nosti osushchestvleniya okhrany obshchestvennogo poryadka organami mestnogo samoupravleniya // Munitsipal'naya sluzhba: pravovye voprosy. 2014. - № 1. - S. 6-9.

18. Zakon Vladimirskoi oblasti ot 30.12.2002 № 141-OZ «Ob administrativnykh komissiyakh» // Vladimirskie vedomosti. № $5 .-10.01 .2003$.

19. Zakon Vladimirskoi oblasti ot 11.07.2014 № 79-OZ «O komissiyakh po delam nesovershennoletnikh i zashchite ikh prav vo Vladimirskoi oblasti» // Vladimirskie vedomosti. - № 136. - 19.07.2014.

20. Postanovlenie glavy okruga Murom ot 07.12.2011 № 3492 «O sozdanii administrativnykh komissii № 1 i № 2 munitsipal'nogo obrazovaniya okrug Murom» // Dostup iz sprav.-pravovoi sistemy «Konsul'tantPlyus».

21. Postanovlenie administratsii goroda Vladimira ot 19.12 .2011 № 4059 «Ob utverzhdenii personal'nogo sostava administrativnoi komissii munitsipal'nogo obrazovaniya gorod Vladimir (gorodskoi)» // Periskop. - № 204. - 24.12.2011.

22. Postanovlenie glavy Aleksandrovskogo raiona ot 24.01 .2011 № 272 «Ob utverzhdenii administrativnykh reglamentov po ispolneniyu munitsipal'nykh funktsii komissiei po delam nesovershennoletnikh i zashchite ikh administratsii Aleksandrovskogo raiona» // Aleksandrovskii golos truda. - № 15. - 13.04.2011.

23. Proekt Federal'nogo zakona № 621910-6 «0 munitsipal'noi militsii v Rossiiskoi Federatsii» nakhoditsya na rassmotrenii Gosudarstvennoi Dumy FS RF.

24. Federal'nyi zakon ot 02.04.2014 № 44-FZ «Ob uchastii grazhdan v okhrane obshchestvennogo poryadka» // SZ RF. 2014. - № 14. - St.1536.

25. Zakon Vladimirskoi oblasti ot 10.06 .2013 № 60-OZ «Ob uchastii grazhdan v okhrane obshchestvennogo poryadka na territorii Vladimirskoi oblasti» // Vladimirskie vedomosti. - № 107. - 15.06.2013.

26. Reshenie Soveta narodnykh deputatov Selivanovskogo raiona ot 28.08.2013 № 75 «Ob utverzhdenii Polozheniya ob uchastii grazhdan v okhrane obshchestvennogo poryadka na territorii Selivanovskogo raiona» // Selivanovskii vestnik. № 54. - 30.08.2013.

27. Reshenie Soveta narodnykh deputatov ZATO g. Raduzhnyi ot 16.09.2013 № 15/79 «Ob utverzhdenii Polozheniya o sozdanii uslovii dlya deyatel'nosti dobrovol'nykh formirovanii naseleniya po okhrane obshchestvennogo poryadka na territorii ZATO g. Raduzhnyi Vladimirskoi oblasti» // Raduga-inform. - № 65. - 20.09.2013.

28. Federal'nyi zakon ot 25 dekabrya 2008 g. № 273-FZ «O protivodeistvii korruptsii» // SZ RF. - $2008 .-$ № 52 (ch. 1). St. 6228; - 2014. - № 52 (chast' I). - St. 7542.

29. Postanovlenie glavy Selivanovskogo raiona ot 25.05.2012 № 485 «Ob utverzhdenii plana «Protivodeistvie korruptsii v munitsipal'nom obrazovanii Selivanovskii raion na 2012-2014 gody» // Dostup iz sprav.-pravovoi sistemy «Konsul'tantPlyus».

30. Postanovlenie administratsii munitsipal'nogo obrazovaniya gorod Kameshkovo Kameshkovskogo raiona Vladimirskoi oblasti ot 16.07.2014 № 106 «Ob utverzhdenii polozheniya o poryadke i srokakh primeneniya vzyskanii k munitsipal'nym sluzhashchim administratsii munitsipal'nogo obrazovaniya gorod Kameshkovo Kameshkovskogo raiona za nesoblyudenie ogranichenii i zapretov, trebovanii o predotvrashchenii ili ob uregulirovanii konflikta interesov i neispolnenie obyazannostei, ustanovlennykh v tselyakh protivodeistviya korruptsii» // Dostup iz sprav.-pravovoi sistemy «Konsul'tantPlyus».

31. Postanovlenie administratsii Petushinskogo raiona ot 28.02.2014 № 396 «Ob utverzhdenii munitsipal'noi programmy «Protivodeistvie korruptsii v munitsipal'nom obrazovanii «Petushinskii raion» na 2014-2016 gody» // Vpered. - № 31. 4-10 iyulya. - 2014.

32. Reshenie Soveta narodnykh deputatov okruga Murom ot 22.02.2011 № 1220 «Ob utverzhdenii perechnya dolzhnostei munitsipal'noi sluzhby, predusmotrennogo stat'ei 12 Federal'nogo zakona ot 25.12.2008 № 273-FZ «0 protivodeistvii korruptsii» // Muromskii krai (dokumenty, vypusk № 15). - № 32. - 01.03.2011.

33. Kamilov M.A. Opredelenie obshchestvennoi bezopasnosti v sootvetstvii s novoi Kontseptsiei obshchestvennoi bezopasnosti v Rossiiskoi Federatsii. // Administrativnoe i munitsipal'noe pravo. - 2014. - 8. - C. 775 - 778. DOI: 10.7256/1999-2807.2014.8.12403. 